\title{
THE DEVELOPMENT OF DECISION EVALUATION MODEL (DEM) TO DETERMINE BETWEEN MANUFACTURING OFF-SITE OR ON-SITE METHODS FOR THE CONSTRUCTION OF HOUSE BUILDING PROJECTS
}

\author{
Hussein Elnaas ${ }^{\dagger}$ \\ School of Environment and Technology, \\ University of Brighton, Brighton, East Sussex, BN2 4GJ, UK \\ Tel: +44-1273-642284, Email: E.Elnaas@brighton.ac.uk \\ Kassim Gidado ${ }^{1}$ and Philip Ashton ${ }^{2}$ \\ ${ }^{1,2}$ School of Environment and Technology, \\ University of Brighton, Brighton, East Sussex, BN2 4GJ, UK \\ ${ }^{1}$ Tel: +44-127364-2394, Email: k.i.gidado@brighton.ac.uk \\ ${ }^{2}$ Tel: +44-127364-2388, Email: P.Ashton@brighton.ac.uk
}

\begin{abstract}
It is a common statement that construction decisions are described as difficult, because typically they involved high uncertainty, complexity, risk consequences, alternative construction methods and products, and numerous stakeholders with different interest. This research focuses on choosing a construction strategy between off-site manufacturing systems and on-site methods for a project. This requires an optimum decision strategy which involves careful understanding, measurement and evaluation of a number of factors that can have the most influence on alternate decision outcomes. The aim of this paper is to describe the development of a Decision Evaluation Model (DEM) that provides a clear cut choice between using offsite manufacture and onsite construction methods at the pre-construction stage for house building projects. Having carried out an extensive literature review, primary research data and information was collected using 30 semi-structured interviews, questionnaires completed by 30 carefully selected respondents, and 30 case studies made up of 15 projects that used 'off-site' manufacturing and 15 other projects using 'onsite' construction methods. A robust set of factors have been identified, measured and ranked according to their significance on the decision. Using these factors, a methodology has been developed to measure and evaluate the characteristics of a project, which forms the core of the DEM and further case studies were used to test the validity of the developed model. The primary objective of the model is to improve the quality of information on which the decision is based and to enable decision makers to clearly establish whether to use 'offsite' or 'onsite' as a construction strategy.
\end{abstract}

Keywords: Decision Making, Decision Evaluation Model, Decision Strategy, Off-Site Manufacturing (OSM)

\section{INTRODUCTION}

The demand for supplying high-quality homes in less time with low-cost products and lower environmental impacts has driven the industry to review its operation and seek ways of improving its management process by adopting more innovation and manufacturing technologies in the construction. Since 1998 when Egan recommends the use of offsite

$\dagger$ Corresponding author 
innovations in construction (Egan Report, 1998), the UK house building industry has faced additional demands such as: the call for a reduction in $\mathrm{CO} 2$ emission and the environmental impacts of buildings, shorter project duration and costs savings, reduction in defects, elimination of accidents and ill health, and improvement in house building supply rate (NHBC House, 2009; Ross et al., 2006 and Housing Forum, 2004). Experts have suggested that traditional form of construction is failing to meet these and future demands. Blismas and Wakefild (2007) stated that Off-Site Manufacturing (OSM) can contribute to meeting some of these demands facing the construction industry.

Housing Corporation (2007) suggests that the potential of using OSM may be a key vehicle to drive the process of efficiency improvements within the house building sector. However, despite this opportunity, Goulding et al., (2012) stated that the uptake of OSM is much lower than expected in the UK construction industry. The reason for this has been identified to hinge on the many issues and questions that need to be addressed within the client's or the practitioners' decision making process that leads to the use of OSM particularly for building projects. This work provides the evidence to support the need for the development of a new model to assist the construction professional to make decisions on whether to use offsite systems or onsite methods of construction particularly for house building projects.

\section{THE NEED TO ESTABLISH THE CONTEXT OF THE DECISION MAKING PROCESS}

Whilst there exists decision support systems and evaluation techniques, Pasquire and Gibb (1999) argued that decisions to use offsite techniques in construction are still largely based on unreliable/subjective evidence rather than accurate data, as no formal measurement procedures or strategies are available. Further, Blismas et al (2006) stated that the decision making process that is used to evaluate to what extent a component or a building system should be produced offsite is inadequate. Elnaas et al (2012) argued that despite the wealth of knowledge and information available in the UK, the house building industry seems to be failing to use existing models and systems designed to improve decision making.

Industry professionals have expressed their interest in the process of Off-Site Manufacturing (OSM) systems in construction, however due to the lake of expertise in the area of OSM decision making, some professionals have simply avoided the use of these technologies (Ogden, 2010). A major reason, established by Pasquire and Gibb, (2002) is that contractors are unwilling to adopt OSM because they have difficulty ascertaining the benefits that would add to their individual project.

CIRIA (2000) reported that the decision making process used to evaluate the application of OSM in the construction process is poorly understood. Pasquire et al (2004) have re-emphasised the inadequacy of the decision making process, while Blismas et al., (2006) said that decisions regarding the use of OSM are often unclear and complex. Pasquire and 
Gibb (2002) added that the decisions used in the construction industry seem to be based on anecdotal evidence rather than reliable data, as no formal measurement procedures or strategies are available. Pan et al (2008) reminded practitioners that with increasing pressure on construction professionals to improve efficiency and to make decisions quickly, there is a lack of rational, robust and balanced decision criteria for building system selection in house building.

The literature review clearly indicates that there has been very little evidence to suggest that the existing decision making systems designed in the context of OSM are meeting the current needs of the construction practitioners. Therefore, there is a need for a mechanism to be designed based on robust knowledge of decision making methodology in the house building industry.

Elnaas et al., (2012) defined that decision making is an on-going task, carried out throughout the project life cycle and it is the process of problem solving activity, through making a conscious choice or selecting to achieve an objective or desirable outcome. Further, Lucey (1997) stated that making decisions must decide by some means to choose the outcome or outcomes which are desirable to decision maker(s) and to do so after some form of appraisal of the situation. While, Choo (2006) declared that an alternative decision is considered most favourable if it is greater to all other alternatives when a single, consistent set of criteria is used to compare all the available alternatives. Abdullah and Egbu (2010) argue that the best decision should be supported with sufficient information and knowledgebase of the decision making context.

In this research, the context of making the decision is to determine and choose between manufacturing OSM systems or onsite methods as a construction strategy for house building projects. This will require an optimum decision strategy which involves careful understanding, measurement and evaluation of a number of drivers, constraints and factors that can have the most influence on successful decision making process.

\section{THE DEVELOPMENT OF DECISION EVALUATION MODEL (DEM)}

Blismas et al (2006) argued that the evaluation method used within conventional decision making process is often by considering cost of materials, labour and transport and its associated costs into account when comparing various construction methods. While other sources of value, such as quality, health and safety, process, procurement benefits are not often evaluated in monetary context, either implicit or overlooked within the selection. Further, Laing et al (2008) stated that the large majority of cost modelling work focused onsite work, but a detailed appraisal of offsite procedures would in itself be a useful outcome. They also argued that accuracy in estimating must be drawn from an understanding of the factors in a given situation, rather than relying on a general mathematical technique. Thus, the new model was developed to address this significant challenge rather than to make decision based on subjective evidence. 
A critical success factor for any model that is expected to be used by practitioners is its user friendliness and simplicity. The proposed conceptual model is shown in Figure 1, made up of four major processes or phases. The four processes were identified by this research whilst analysing the data and information collected from the interviews, questionnaires and case studies as part of the model development stage of the research.

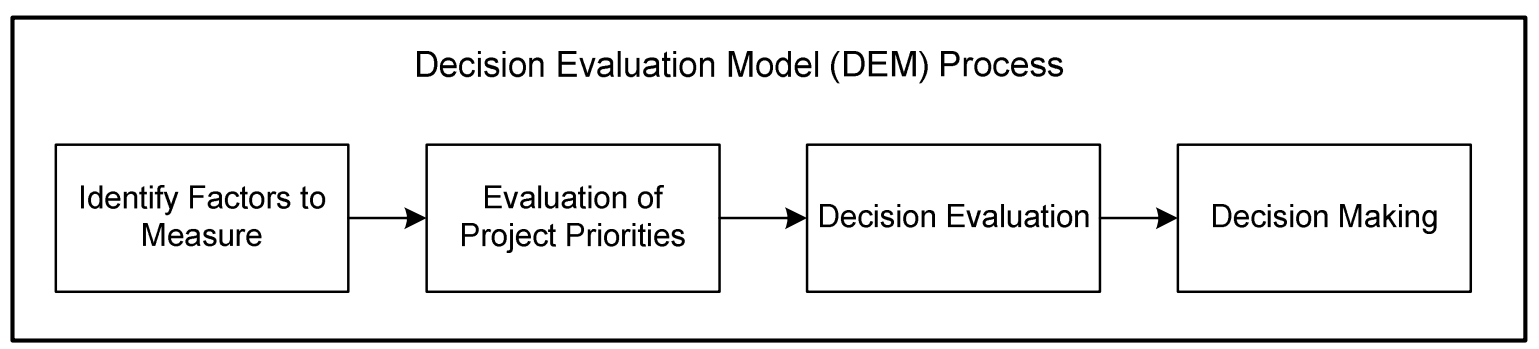

Figure 1: Illustrates the processes of Decision Evaluation Model (DEM)

The first phase of the model deals with strategic planning of the project from the client's statement of need, brief development to project scheme development. It involved basically the identification of project priorities. Phase two involved the establishment of a means of measuring the impact of the 16 theme factors based upon the project in question. As part of the third phase, the severity index was developed using the importance and significance indexes of the factors to be used as database for the evaluation of decision. Phase four involved the development of mechanism for evaluating project characteristics in order to make a decision on whether to use offsite or onsite construction methods based on adequate data and predictable outcomes.

Mixed methods were employed throughout this research using both qualitative and quantitative approaches for data gathering including literature search and review, semi-structured interview, questionnaire survey and case studies. A total of 30 interviews were carried out using semi-structured form with leading construction professionals and members of BuildoffSite (BoS) organisation. All the interviewees were senior managers and directors with responsibility for making company policy decisions including clients, contractors, consultants, project managers, design managers and construction managers. This mixed range of views and opinions explored how decisions to use OSM systems were currently being made in the house building industry.

A further 30 case studies, which included 15 projects using OSM systems and 15 projects using on-site construction methods, were conducted. This provided a comprehensive set of factors and the impact of each factor on the outcome of the decision made when considering to use or not to use OSM systems for house building projects. This research has focused on typical domestic housing developments consisting of one to four bedroom homes, flats, apartments or accommodations units.

A questionnaire survey targeted house builders using the data obtained from construction 
professionals on decision making to use of OSM systems; and further explored how decisions to use onsite construction methods were currently made within the industry. The survey was sent out to the top $100 \mathrm{UK}$ construction contractors involved in house building projects. The questionnaire has been designed in a manner to enable respondent to answer either from past experience or from current on-going projects. There were 36 responses collected but only 30 were included in the data analysis simply to equal the number of interviews that have been conducted.

The outcomes of which were used to establish 16 themes of decision factors and a selection criteria. The data obtained from both offsite and onsite studies were analysed using a five point likert scale. In order to derive frequency index, importance index and significance index for each factor. The frequency index $\left(\mathrm{F}_{\mathrm{i}}\right)$ was derived and established using the following function:

$$
F_{i}=100 \sum(f / F)
$$

Where:

$\mathrm{f}=$ frequency of possible weighting

$\mathrm{F}=$ total number of respondents

Whilst, the importance index $\left(\mathrm{I}_{\mathrm{p}}\right)$ is established using the following function:

$$
I_{p}=100 \sum(a f) / A F
$$

Where:
$\mathrm{a}=$ the weighting
$\mathrm{A}=$ maximum possible weighting
$\mathrm{f}=$ frequency of possible weighting
$\mathrm{F}=$ total number of respondents

Moreover, the importance indices were used to calculate a significance index (SI) for each factor on both offsite and onsite data using the following equation:

$$
S I=\text { Importance index }\left(I_{p}\right) \times \text { Frequency index }\left(F_{i}\right)
$$

Having established the importance and significance indices of the sixteen themes of decision factors, the severity indices $\left(\mathrm{S}_{\mathrm{v}} \mathrm{I}\right)$ are calculated as the difference between significance indices of 'offsite' and that of 'onsite' for each theme in the matrix. If the value of severity index of a factor is positive $(\geq 0)$, then the decision favours using offsite. However, if the value is negative $(<0)$, it means that the decision is in favour of using onsite construction methods for a given project.

The decision maker may need to come back and check the impact and interrelationship of the importance indices of some factors if the value of severity index of a factor is equal 
zero $(=0)$. The severity index matrix could be presented using a simple Microsoft Excel spread sheet, which should give a summary of all information of the theme decision factors.

\section{APPLICATION OF DECISION EVALUATION MODEL (DEM)}

To apply the developed Decision Evaluation Model (DEM), the model has been adapted to comprise of four phases as shown in Figure 2.

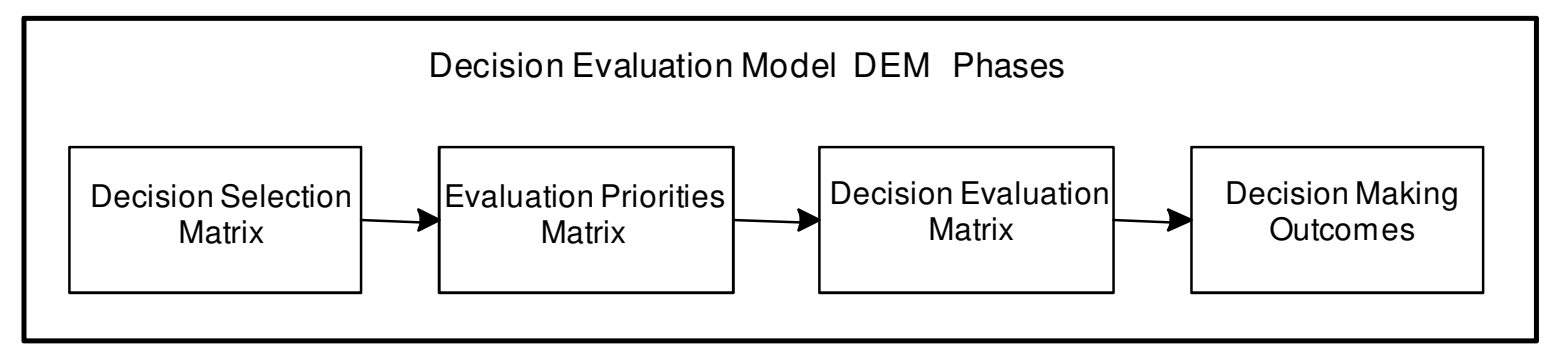

Figure 2: Decision Evaluation Model DEM (adopted from Figure 1)

The four phases are detailed as following:

\section{Phase 1 - Decision Selection Matrix}

The DEM model begins in phase 1 with the evaluation of client's statement of need and the outcome of brief development, in order to identify project priorities and desirable outcomes for the project. The project priorities need to be set and named according to the established 16 themes of decision factors (labelled A to P) that need to be considered based upon their significance on the project.

This phase is the only stage that the user of the model inputs data into the model. The user is to study his/her project and identify the priority issues that impact on perceived project success and place these into the established 16 themes of decision factors (i.e. A: Time, B: Quality, C: Cost, D: Predictability, etc.). As shown in Figure 3, the user will then evaluate these factors by using the Paired Wise Comparison for each two variables of the 16 themes. Each box in this matrix represents a question phrased "in this project which is more important to you as a decision maker to meet the client's need or towards achieving the desired project outcomes?" and the user is to type in the box the code of the factor that adds greater value to the project depended upon its set priorities. This means that each single factor will be evaluated against the other 15 factors in the matrix.

\section{Phase 2 - Evaluation Priorities Matrix}

The second phase focuses on the evaluation of the project priorities by establishing the number of times each factor is selected against each other and calculating the percentage of the total out of the maximum number of occurrence (i.e. 16). The function used to derive the number of Occurrence $\left(\mathrm{O}_{\mathrm{i}}\right)$ of each factor is as follows: 
$\mathrm{O}_{\mathrm{i}}=\sum\left(\mathrm{a}_{\mathrm{i}} \times \mathrm{f}_{\mathrm{i}}\right)$

Where:

$\mathrm{a}=$ weighting $=1$ (since each factor is presently assumed to be equally weighted)

$\mathrm{f}=$ number of times the factor is considered superior.

Similarly, the Frequency Index (Fi) is calculated as follows:

$\mathrm{Fi}=100 *\left(\mathrm{O}_{\mathrm{i}} / \mathrm{F}\right)$

Where:

$\mathrm{O}_{\mathrm{i}}=$ number of Occurrence for each factor

$\mathrm{F}=$ total number of possible factors $=16$

The Rating $\left(\mathrm{R}_{\mathrm{i}}\right)$ is simply the ranking of the factors based upon their relative significance, which is automatically generated using the values of the frequency indexes. This ranking system puts in order of significance the factors that can have the most influence on the decision using F1 to F16; where F1 is given to the factor with the highest value of Ri, through to F16 being the lowest ranked factor as shown in Figure 3.

DECISION EVALUATION MODEL (DEM)

\begin{tabular}{|l||l||}
\hline CUENT & \\
\hline PROEET REF. & \\
\hline PROJECT NAME & \\
\hline PROIEC LOCATON & \\
\hline
\end{tabular}
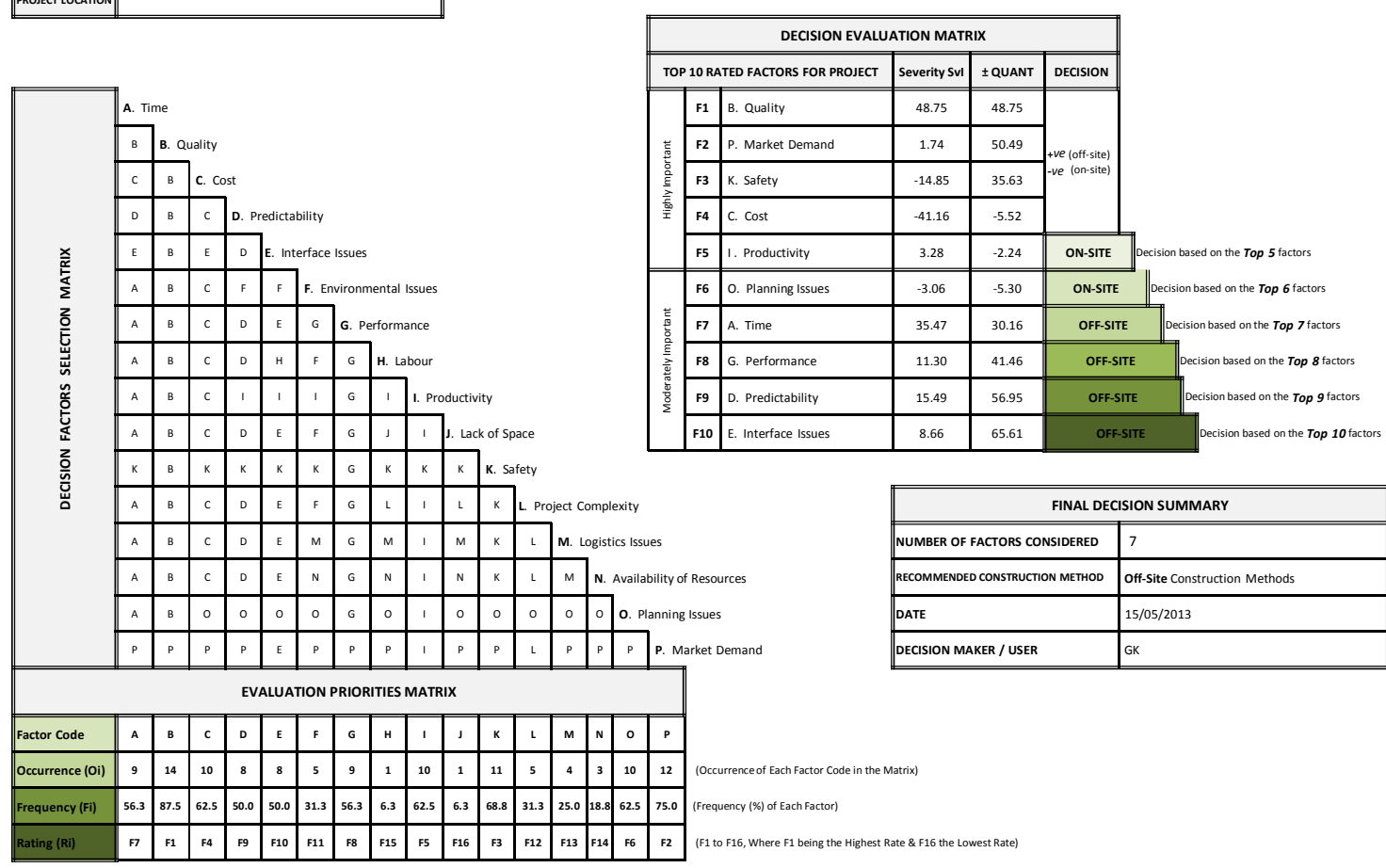

Figure 3: Illustrates the Application of the Decision Evaluation Model (DEM) 


\section{Phase 3 - Decision Evaluation Matrix}

Using the example shown in Figure 3, the Decision Evaluation Matrix takes the top ten ranked factors after careful consideration of the overall significance of the chosen factors. This means that there seems to be relatively less important effect of the last 6 factors on the desired project outcome therefore they can arguably be discarded.

One of the key contributions of this research project was the establishment of Severity Index values and Importance Index values for each of the 16 theme factors as shown in Table 1. Using these values, the established severity index will then be recorded for each of the 10 selected factors in column four of the Decision Evaluation Matrix in Figure 3. The Quant index $\left({ }_{Q}\right)$ is also calculated using the severity indices and recorded in the fifth column of the matrix. The corresponding Quant index value for each factor is simply the Quant index of the previous top factor minus the severity index value of the factor (the Quant index of first factor F1 is equal to its Severity index value). The sixth column will automatically indicate the decision to use 'offsite' if the corresponding Quant index $\left({ }_{Q i}\right)$ value is greater than or equal zero $(\geq 0)$ i.e. +ve value. In contrast to this, the decision is to use 'onsite' at any factor if its corresponding value is less than zero $(<0)$ or if the value is simply a negative $(-v e)$ value.

Table 1: Severity Index Matrix for 16 Theme Factors of OSM

\begin{tabular}{|c|c|c|c|c|c|c|}
\hline \multirow{2}{*}{ Factors } & \multicolumn{2}{|c|}{$\begin{array}{c}\text { Significance } \\
\text { Index }\end{array}$} & \multicolumn{2}{|c|}{$\begin{array}{c}\text { Importance } \\
\text { Index }\end{array}$} & \multicolumn{2}{|c|}{$\begin{array}{c}\text { Severity } \\
\text { Index }\end{array}$} \\
\hline & off & on & off & on & SI & Ip \\
\hline Time & 95.56 & 60.09 & 95.56 & 69.33 & 35.47 & 26.22 \\
\hline Quality & 72.48 & 23.73 & 79.56 & 39.56 & 48.75 & 40.00 \\
\hline Cost & 52.62 & 93.78 & 64.00 & 93.78 & -41.16 & -29.78 \\
\hline Predictability & 27.93 & 12.44 & 44.89 & 28 & 15.49 & 16.89 \\
\hline Interface Issues & 16.51 & 7.85 & 33.78 & 23.56 & 8.66 & 10.22 \\
\hline Environmental Issues & 16.58 & 5.81 & 32.44 & 18.67 & 10.78 & 13.78 \\
\hline Performance & 18.25 & 6.95 & 34.22 & 19.56 & 11.30 & 14.67 \\
\hline Labour & 13.69 & 22.63 & 29.33 & 35.11 & -8.94 & -5.78 \\
\hline Productivity & 14.73 & 11.45 & 31.56 & 27.11 & 3.28 & 4.44 \\
\hline Lack of Space & 17.60 & 11.07 & 36.00 & 26.22 & 6.53 & 9.78 \\
\hline Safety & 7.43 & 22.28 & 20.89 & 41.78 & -14.85 & -20.89 \\
\hline Project Complexity & 5.52 & 13.47 & 19.11 & 27.56 & -7.95 & -8.44 \\
\hline Logistics Issues & 5.93 & 40.44 & 17.78 & 52 & -34.52 & -34.22 \\
\hline Availability of Resources & 3.15 & 13.04 & 12.89 & 26.67 & -9.89 & -13.78 \\
\hline Planning issues & 1.19 & 4.25 & 6.67 & 19.11 & -3.06 & -12.44 \\
\hline Market Demand & 4.35 & 2.61 & 17.78 & 14.67 & 1.74 & -3.11 \\
\hline
\end{tabular}

\section{Phase 4-Decision Making Outcomes}

Where the outcome is consistent for each factor, the decision is straightforward. However, where there is both -ve and +ve Quant values in the various factors, the user or decision maker has an essential role in arriving at the final decision. He/she is expected to use his/her experiences and knowledge to decide which or how many factors out of the listed should or must be considered among the top ranked factors that have the most effect on 
achieving the desired project outcomes. The guided decision is then recorded in the final decision summary box.

In the example shown in Figure 3, if the decision maker chose a cut-off point on the list of considered factors at any one of the following factors, the recommended decision would be to use 'offsite': F1, F2, F3, F7, F8, F9 and F10. However, if for instance he/she chose to consider only the top 4 or top 5 or even top 6 factors, the recommended decision would be to use 'onsite'. In this case study project, the decision maker chose to use top 7 factors, therefore the recommended decision is to use 'off-site' with a Quant index value of 30.16. This means that the recommended decision will always be influenced by number of factors to be considered since it is based upon the Quant index value of the final factor chosen. It then means that if any factor that the decision maker considers as a priority fails to appear amongst the top 10 it means that there must have been an error in the input of data at phase 1 . In such a case, the user/decision maker may need to go back to the First phase of the model to review his/her input data, in order to make the right decision based on project priorities and desired outcomes.

\section{TESTING THE 'DEM' MODEL}

In order to test and validate the model, three live case study projects at their planning stage were analysed. These case studies were selected using the same selection criteria that were used for the original case studies used during the model development stage. Absolute access to all case study scheme data provided a unique opportunity to evaluate the project characteristics based on desired outcomes and client's statement of need. The application of the model was absolutely operated by the project manager of each case study project to complete the exercise. This gave the opportunity to assess the friendliness of the user-interface of the model. Each of the test case studies is discussed as follows:

\section{Case Study AS-P}

The case study referred to as AS-P was a new housing development and comprises 51 residential units. The project located in an extremely busy city centre with restricted site layout, listed adjacent buildings from one side and heritage/historic elements attached to another building from another side, and underground train line is also crossing under one angle of the building site. The testing was during pre-tender stage of its life cycle stages. Based on the evaluation process of the model, the decision indicated to use 'off-site' methods as a construction strategy based on deliberation and the inclusion of top 8 factors that have most influence on decision outcome. These factors were time, quality, cost, predictability, market demand, project complexity, planning issues and safety.

\section{Case Study MR-P}

The MR-P was a residential development and comprises 48 units include one, three and four bedroom flats. This project is in central city location with restricted site layout. The testing took place during the planning stage of the project. The assessment of whether to use 
off-site or on-site methods indicated that 'on-site' methods was recommended as a construction strategy based on the top 9 factors considered to have most priorities for the project. These factors were market demand, lack of space, project complexity, planning issues, time, safety, logistics, cost and quality respectively.

\section{Case Study FR-P}

The third case study FR-P was a small project of housing development contains 13 houses of one and three bedroom homes. The project is located close to central location in a quite open area adjacent to a park which can be used as additional storage space during the construction. The testing took place during the planning stage of the project. Having identified the top factors to be considered, the model indicated off-site construction strategy. Further, the inclusion of top 7 factors which were quality, market demand, safety, cost, predictability, planning issues and time confirmed that the off-site construction strategy should be used for this project. The information and results of DEM model shown in the Figure 3 was the evaluation of the decision process of this case study. The final decision was based on the top 7 factors which have had most significant influence on project desirable outcomes.

\section{CONCLUSION}

The house building industry has the potential to address some of the challenges facing the UK construction industry. The study highlighted that traditional construction methods have struggled to meet these demands. This research concurs with others that suggest that the use of OSM systems could contribute to achieving government and industry targets. In order to achieve these improvements, decision making to choose 'offsite' or 'onsite' needs to be better understood. The developed Decision Evaluation Model (DEM) presented in this paper will enable this to be realised at the same time ensuring the output of the model clearly ascertain the benefits to be added (Pasquire and Gibb, 2002), it must be clear and un-complex (Blismas et al, 2006), it must be based on reliable data (Pasquire and Gibb, 2002), and it must have rational, robust and balanced decision criteria (Pan et al, 2008).

The paper makes a significant contribution in two aspects: Firstly, it has established a robust set of decision factors that need to be considered and the establishment of a Severity Indices Matrix that maps the importance or the significance or the impact of these factors on successful delivery of the project particularly for house building-type projects; Secondly, since there is currently no formal method or decision support system used within the industry, the paper has developed a new decision making support system, DEM.

The DEM functions by taking factors that have most influence on the project, and then measure and rank each of these factors by regarding their significance on the decision whether to use offsite against onsite construction method strategy. The project decision is quantified based upon the evaluation and priorities for project, using the established database of the severity indices of those factors.

The three case studies were analysed in order to test the validity of the model at their 
pre-construction stage. The testing has been carried out on real life construction housing projects that are of different scales and different project conditions. The key aim was to identify whether there were any problems concerning the workings of the model. Each test case study had different project priorities on which the decision was based and the results provided overwhelming evidence to suggest that the model is able to produce a clear recommendation on whether to use OSM systems or on-site systems as construction strategy for each project. It was concluded that the model works well and found to be simple to use and user-friendly and it minimises the time and the quantity of data required by the user to complete the exercise of the evaluation.

The DEM model can be used in practice to structure the decision making process, improve the quality of information on which the decision is based, and provide the opportunity to assist practitioners in making decisions based on appropriate and adequate data within the project environment. Obtaining the right construction strategy impacts greatly on the probability of achieving project success and best fits with the project goals.

\section{REFERENCES}

Abdullah, M. And Egbu, C. (2010) Selection Criteria Framework for Choosing Industrialized Building Systems for Housing Projects. Procs 26th Annual ARCOM Conference, Leeds, UK, 1131-1139.

Blismas, N. and Wakefield (2007) Drivers, Constraints and the Future of Off-Site Manufacture in Australia. Produced by CRC for Construction Innovation Special Edition 2008. QUT, 27575.

Blismas, N., Gibb, A. and Pasquire, C. (2006) Benefit Evaluation for Off-Site Production in Construction. Construction Management and Economics, 24 (2), February 2006, pp. 121-130, ISSN 01446193.

Choo, C. (2006) The Knowing Organization: How organizations use information to construct meaning, create knowledge and make decisions. The $2^{\text {nd }}$ ed. Oxford University Press, Oxford, UK.

CIRIA and principal author Gibb, A. (2000) Client's Guide and Tool Kit for Standardisation and Pre-assembly. Construction Industry Research and Information Association (CIRIA), 2000, Report CP/75, 70 pp. ISBN 0860175448.

Egan, J. (1998) Rethinking Construction: Accelerating Change. Department of the Environment, Transport and the Regions, London, UK.

Elnaas, H., Ashton, P. and Gidado, K. (2012) Factors and Drivers Effecting the Decision of Using Off-Site Manufacturing (OSM) Systems in House Building Industry. The 3rd EPPM international Conference, September 2012, Brighton, UK.

Housing Corporation (2007) Modern Talking: Building better value homes using modern approaches. Housing corporation, February 2007, London, UK. 
Housing Forum (2004) Manufacturing Excellence: UK capacity in off-site manufacturing. The Housing Forum, London, UK.

Goulding, J., Rahimian, F., Arif, M. and Sharp, M. (2012) Offsite Construction: Strategic Priorities for Shaping the Future Research Agenda. Architectoni.ca 2012, 1, 62-73.

Laing, R., Craig, A. and Edge, H. (2008) Prefabrication Housing: An Assessment of Cost, Value and Quality. The Robert Gordon University, Adrdeen, UK.

Lucey Terrt (1997) Management Information Systems, 8th ed. DP Publications, London, UK. NHBC House (2009) Defining a Fabric Energy Efficiency Standard for Zero Carbon Homes: Executive Summary of Task Group Recommendations, November 2009, London, UK. Ogden, R. (2010) Year Book: the Buildoffsite vision. July, 2010, Buildoffsite, London, UK. Pan, W., Gibb, A. and Dainty, A. (2007) Perspectives of UK House-builders on the use of Off-Site Modern Methods of Construction. Construction Management and Economics, Vol 25, No 2, 2007, pp. 183-194, ISSN 0144-6193.

Pan, W., Gibb, A. and Dainty, A. (2008) Leading UK housebuilder's Utilisation of offsite modern methods of construction. Building Research and Information, 36(1), 56-67.

Pasquire, C. and Gibb, A. (1999) Considerations for Assessing the Benefits of Standardisation and Pre-assembly in Construction. Report to CIBSE Seminar on standardisation in design and construction of building services installations, 26 October 1999.

Pasquire, C. and Gibb, A. (2002) Considerations for Assessing the Benefits of Standardisation and Pre-assembly. Journal of Financial Management of Property and Construction, 7(3), $151-61$.

Pasquire, C., Gibb, A. and Blismas, N. (2004) Off-Site Production: Evaluating the Drivers and Constraints. Proceedings of the 12th Annual Conference on Lean Construction, Copenhagen, Denmark, 3-4 August.

Ross, K., Cartwright, p. and Novakovic, O. (2006) A Guide to Modern Methods of Construction. The BRE Housing Innovation Centre Published by IHS BRE Press on behalf of NHBC Foundation. 